\title{
Cloning, Expression, and Promoter Analysis of Hepatic Lipase Derived From Human Hyperplastic Adrenals
}

\author{
Evidence for Alternative mRNA Splicing \\ Gert-Jan Botma, ${ }^{1}$ Mirjam Heuveling, ${ }^{1}$ Jos M.J. Lamers, ${ }^{1}$ \\ Hans Jansen, ${ }^{1,2}$ and Adrie J. M. Verhoeven ${ }^{1, *}$ \\ ${ }^{1}$ Departments of Biochemistry and ${ }^{2}$ Clinical Chemistry, Cardiovascular Research School COEUR, \\ Erasmus MC, Rotterdam, The Netherlands
}

\begin{abstract}
Human adrenals contain hepatic lipase (HL) activity, which is thought to facilitate the uptake of plasma cholesterol used in steroidogenesis. We show here that full-length HL mRNA is expressed in hyperplastic adrenals of patients with Cushing's disease. In addition, a splice variant that lacks exon-3 was detected in the human adrenals and hepatoma (HepG2) cells, but not in liver. In CAT-reporter assays using human NCI-H295R adrenocortical cells, the HL $(-685 /+13)$ promoter region was transcriptionally active, and its activity was enhanced twofold by cAMP. In rat adrenals, the HL gene is exclusively transcribed from an alternative promoter within intron-2, resulting in a variant mRNA that lacks exons 1 and 2. By reverse-transcription PCR, we found no evidence for expression of such a variant mRNA in human adrenals, liver, or HepG2 cells. The presence of both fulllength mRNA and enzyme activity in human adrenals suggests that part of the HL activity is locally synthesized.
\end{abstract}

Index Entries: Hepatic lipase; human liver; human adrenal; Cushing's disease; RT-PCR; alternative splicing.

\section{INTRODUCTION}

Hepatic lipase (HL; E.C. 3.1.1.34) activity is present in the adrenal cortex of several mammals including man (1-4), as well as in rat ovaries (5-8). The HL activity from rat, mouse, and human adrenals is indistinguishable from HL in liver and post-heparin plasma $(2,5$, $8-10)$. In the liver, HL activity plays an important role in plasma lipoprotein metabolism (11). Notably, the enzyme facilitates the cellular uptake of cholesterol carried in high-density lipoprotein (HDL) $(12,13)$. Several lines of evidence indicate that the HL activity in the steroidogenic organs is also involved in the uptake of cholesterol necessary for steroid production $(6,8,14,15)$, probably by accelerating the SR-BI mediated uptake of HDL cholesterol $(16,17)$.

\footnotetext{
*Author to whom all correspondence and reprint requests should be addressed. E-mail: a.verhoeven@erasmusmc.nl
}

It is generally assumed that the HL activity found in steroidogenic organs is not locally synthesized, but originates from liver and is transported to these organs via the circulation $(4,7,9)$. This is mainly based on the inability to detect full-length HL mRNA $(7,9,18-20)$ and de novo synthesis of HL protein $(9,18-20)$ in extrahepatic tissues of the rat. HL protein is present in rat plasma associated with HDL (4), and rat ovaries were shown to accumulate HL from the circulation (7). However, expression of HL mRNA and synthesis of HL protein have now been demonstrated in adrenals of neonatal mice (10) and in human and mouse macrophages (21). We recently showed that the HL gene is transcribed in rat adrenals and ovaries, but exclusively from an alternative promoter within intron-2 $(19,20,22)$. This gave a variant HL mRNA product in which the first two coding exons of the HL gene are substituted by a sequence that corresponds to intron-2 immediately upstream of exon-3. In addition, local synthesis of a possible translation product of $45-47$ 
$\mathrm{kDa}$ that cross-reacts with poly- and monoclonal anti-HL antibodies was observed. The variant transcript is also present in rat liver as a small fraction of total HL gene products $(19,22)$. These observations open the possibility that, besides liver-derived HL, rat steroidogenic organs contain a second HL gene product with a hitherto undefined function in steroidogenesis.

In human adrenocortical tissue, part of the HL mRNA could be detected by reverse-transcription (RT)PCR, demonstrating that the HL gene is transcribed in adrenals not only in rat but also in man (3). The question arises whether in human adrenals the HL gene is also transcribed into a variant mRNA similar to that in rat. We therefore used the RT-PCR approach to study the possible expression of multiple HL gene transcripts in human adrenals as well as in human liver and the human hepatoma cell line HepG2. Our data demonstrate the presence of full-length HL gene transcripts in human adrenals.

\section{MATERIALS AND METHODS}

\section{Patient Material}

Four hyperplastic adrenal glands were obtained from two patients with Cushing's disease who underwent bilateral adrenalectomy. A human liver sample was obtained from a patient who underwent liver transplantation. The tissues were kept on ice, rinsed in ice-cold phosphate-buffered saline (PBS), cut into small pieces, and then dropped in liquid nitrogen within 1-2 $\mathrm{h}$ after surgery. Tissues have been stored at $-80^{\circ} \mathrm{C}$ until use.

\section{Cell Lines}

HepG2 human hepatoma cells were cultured in T75 flasks (Nunc, Roskilde, Denmark) at $37^{\circ} \mathrm{C}$ and $5 \% \mathrm{CO}_{2}$ in Dulbecco's modified Eagle's medium (DMEM) (ICN, Costa Mesa, CA) supplemented with $10 \%$ (v/v) fetal calf serum (Gibco, Breda, Netherlands) and penicillin/streptomycin. NCI-H295R human adrenocortical cells were cultured in T25 flasks in DMEM/Ham F12 medium (Gibco), supplemented with $2 \%$ fetal calf serum, $15 \mathrm{mM}$ HEPES, $25 \mathrm{mM} \mathrm{NaHCO} 3,10 \mu \mathrm{g} / \mathrm{mL}$ of insulin-transferrin-sodium selenite (Roche, Almere, Netherlands), 10 $\mathrm{n} M$ hydroxycortisone (Merck, Darmstadt, Germany), 10 $\mathrm{n} M \quad \beta$-estradiol (Sigma, St. Louis, MO), and penicillin/ streptomycin. Every 7 d, the cultures were split 1:10 and 1:3 into new flasks, respectively. Media were refreshed once a week.

\section{RNA Isolation}

Total RNA was isolated from approx $100 \mathrm{mg}$ of adrenal or liver tissue by the method of Chomczynski and Sacchi (23). Similarly, total RNA was isolated from HepG2 and NCI-H295R cells, each starting from two
T25 flasks of confluent cell culture. Total RNA isolated from $100 \mathrm{mg}$ of liver from a male Wistar rat was used as a reference. RNA concentrations were determined by spectrophotometry at $260 \mathrm{~nm}$ (24). The quality of the RNA preparations was judged from the ratio of $28 \mathrm{~S}$ over $18 \mathrm{~S}$ ribosomal RNA after denaturation and electrophoresis in a $1 \%$ agarose/TBE gel (24).

\section{RT-PCR}

First-strand cDNA synthesis and subsequent amplification by PCR was performed in a single tube starting with $1 \mu \mathrm{g}$ of total RNA, as described previously (19). Notemplate controls as well as no-RT controls were included in each experiment. Oligonucleotides used for amplification of HL cDNA are specified in Table 1. The oligonucleotides int2 and INT recognize intron-2 of the human and rat HL gene, respectively, immediately upstream of exon-3 $(19,25)$. For the amplification of human SR-B1 cDNA, the oligonucleotides $5^{\prime}-\operatorname{cgg}$ at TCA GGG GTG TTT GAA GGC-3' (nt 637-654) and 5'cgg gat CCT GAA TGG CCT CCT TAT CC-3' (nt 12341215) were used as forward and reverse primer, respectively (capital letters correspond to the SR-B1 cDNA sequence, numbering according to Calvo and Vega [26]). All primer pairs used span at least one intron.

\section{Post-PCR Analysis}

PCR products were separated by electrophoresis through a $1 \%$ agarose gel (24). Digestion with restriction enzymes (Roche) was performed directly on the post-PCR mixtures. DNA molecular weight marker VI was from Roche. For Southern blotting, the DNA in the gel was transferred onto Hybond-N (Amersham Biosciences, Amersham, UK) and the membrane was probed either with a ${ }^{32} \mathrm{P}-$-labeled oligonucleotide (HL8 ) or full-length rat HL cDNA. The oligonucleotide was labeled with polynucleotide kinase (Roche) and $\left[\gamma^{-32} \mathrm{P}\right]$ ATP (Amersham); the cDNA was labeled using the Megaprime kit and $\left[\alpha_{-}{ }^{32} \mathrm{P}\right] \mathrm{dCTP}$ (Amersham). Standard hybridization and washing conditions were used (24). The ${ }^{32} \mathrm{P}$-labeled bands on the blot were visualized by autoradiography. The intensities of the PCR bands were assessed by densitometry using the GS-800 Calibrated Densitometer (BioRad, Hercules, CA, USA).

For sequence analysis, the DNA band of interest was purified from the gel by the freeze-squeeze method (24), and the DNA was TA-cloned (27) into pBluescript $\mathrm{KS}^{-}$ (Stratagene, La Jolla, CA). Automated sequencing was performed on an ABI 377 DNA sequencer (Applied Biosystems, Foster City, CA) using the Thermo-sequenase dye terminator kit (Amersham) in conjunction with the vector specific SK primer (Stratagene).

\section{Promoter Activity}

The promoter-reporter plasmids used have been described previously. Of the human HL gene, the -685/ 
Table 1

Primers Used in PCR Analysis of Human and Rat Hepatic Lipase (HL) Gene Expression

\begin{tabular}{llccccc}
$\begin{array}{l}\text { Part of } \\
\text { HL gene }\end{array}$ & Name & Orientation & Species & \multicolumn{1}{c}{ Sequence $\left(5^{\prime} \rightarrow 3^{\prime}\right)$} & nt & Ref. \\
\hline exon 1 & HL-4 & $\mathrm{F}$ & $\mathrm{h}$ & ACC AAG AAA GCC TGG ACC C & $8-26$ & 25 \\
exon 2 & HL-13 & $\mathrm{F}$ & $\mathrm{h}$ & TCT GGT GAT GAT AAT CCA CGG G & $253-274$ & 37 \\
& RHL-13 & $\mathrm{F}$ & $\mathrm{r}$ & TGT CAT GAT CAT CCA CGG G & $267-285$ & 36 \\
exon 3 & HL-12 & $\mathrm{F}$ & $\mathrm{h}$ & CGG CGT GCT AGA AAA CTG G & $286-304$ & 37 \\
& RHL-12 & $\mathrm{F}$ & $\mathrm{r}$ & TGG CTT GCT AGA AAC CTG G & $297-315$ & 36 \\
exon 4 & HL-8 & $\mathrm{F}$ & $\mathrm{h}+\mathrm{r}$ & TAA TTG GGT ACA GCC TGG G & $498-516$ & 36 \\
& HL-9 & $\mathrm{R}$ & $\mathrm{h}+\mathrm{r}$ & GGC ATC ATC TGG AGA AAG GC & $660-641$ & 36 \\
exon 5 & HL-1 & $\mathrm{F}$ & $\mathrm{h}+\mathrm{r}$ & GTG GGC ATC AAA CAG CCC & $701-718$ & 36 \\
& HL-3 & $\mathrm{F}$ & $\mathrm{h}+\mathrm{r}$ & CGG GGG CTC CTT CCA GCC TGG & $741-761$ & 36 \\
exon 8 & HL-2 & $\mathrm{R}$ & $\mathrm{h}+\mathrm{r}$ & CAG ACA TTG GCC CAC ACT G & $1292-1274$ & 36 \\
exon-9 & HL-22 & $\mathrm{R}$ & $\mathrm{h}$ & TGT GAG ATT CTT TAT GTA ATT TTG GC & $1641-1616$ & 25 \\
intron 2 & int & $\mathrm{F}$ & $\mathrm{h}$ & AAA CTA AGG CGA CCC TCC CT & - & 25 \\
& INT & $\mathrm{F}$ & $\mathrm{r}$ & GCA TTG TCC TTG AGC CTG AG & - & 19 \\
\hline
\end{tabular}

F and $\mathrm{R}$, forward and reverse orientation, respectively; $\mathrm{h}$ and $\mathrm{r}$, identical to human and rat sequence, respectively.

+13 region and the $-312 /+13$ region were inserted into the pCAT-Basic reporter plasmid (Promega, Madison, WI) to generate HuHL698-CAT and HuHL325-CAT vectors, respectively (28). Of the rat HL gene, the PstI-XbaI $(-437$ to +9$)$ fragment was used to generate RHL446-CAT reporter vector (22). In intron-2-CAT, the 577 bp HindIIIBglII fragment of the rat alternative promoter region located in intron-2 of the rat HL gene was inserted into pCAT-Basic (22).

At $24 \mathrm{~h}$ before transfection, the NCI-H295R cells were plated in six-well plates at 50\% confluence. Transfections were performed with Lipofectamine-Plus (Invitrogen, Breda, Netherlands) according to the manufacturer's instructions, using $1.0 \mu \mathrm{g}$ CAT reporter and $0.25 \mu \mathrm{g}$ RSV $\beta$-galactosidase expression plasmid per well. Parallel transfections with empty pCAT-Basic plasmids were used as controls. When indicated, synthetic ACTH (Synacthen; Novartis, Basel, Switzerland) or 8-bromo-cyclic AMP (8Br-cAMP; Sigma) was added to the medium $4 \mathrm{~h}$ after transfection at a final $0.4 \mathrm{mU} / \mathrm{mL}$ and $300 \mu \mathrm{M}$, respectively. Fourty-eight hours posttransfection, cell lysates were prepared. CAT and $\beta$-galactosidase expression were determined by enzyme-linked immunosorbent assay (ELISA) (Roche). Promoter activity was expressed as pg $\mathrm{CAT} / \mathrm{ng} \beta$-galactosidase to correct for differences in cell number and transfection efficiency.

HepG2 cells were transfected with the calcium-phosphate co-precipitation method using $10 \mu \mathrm{g}$ of the CAT reporter test plasmid and $0.4 \mu \mathrm{g}$ of the RSV $\beta$-galactosidase expression plasmid (Promega). At $24 \mathrm{~h}$ before transfection, the cells were plated in $60-\mathrm{mm}$ culture dishes at $20-30 \%$ confluence. At $3 \mathrm{~h}$ before transfection, the medium was refreshed. Incubations were continued for $48 \mathrm{~h}$ after transfection, and promoter activity was determined as described above.

\section{Statistical Analysis}

Data are expressed as mean \pm SD. Differences were tested for statistical significance by paired Student $t$-test.

\section{RESULTS}

\section{Human Hyperplastic Adrenals}

With the RNA isolated from a human hyperplastic adrenal, a single major product of $596 \mathrm{bp}$ was generated by RT-PCR using the oligonucleotides HL-1 and HL-2, which recognize both human and rat HL cDNA (Fig. 1). This PCR product was observed with RNA prepared from all four adrenals studied. A similar PCR product was generated with RNA from human liver as well as rat liver (Fig. 1). Digestion of the PCR product from human liver, human adrenals and rat liver with BclI resulted in the predicted product of $545 \mathrm{bp}$. An additional fragment corresponding to $45 \mathrm{bp}$ and $51 \mathrm{bp}$ was generated with the human and rat preparations, respectively, in agreement with the restriction maps of human and rat HL cDNA. PstI digestion of the rat liver PCR product gave the expected 400-bp and 196-bp fragments, whereas the human PCR products were not digested. With $1 \mu \mathrm{g}$ of human or rat adrenal RNA, the 596-bp PCR product became UV-detectable after 28-30 cycles of amplification, whereas with $1 \mu \mathrm{g}$ of rat liver RNA, this band was already observed after 20 cycles. 


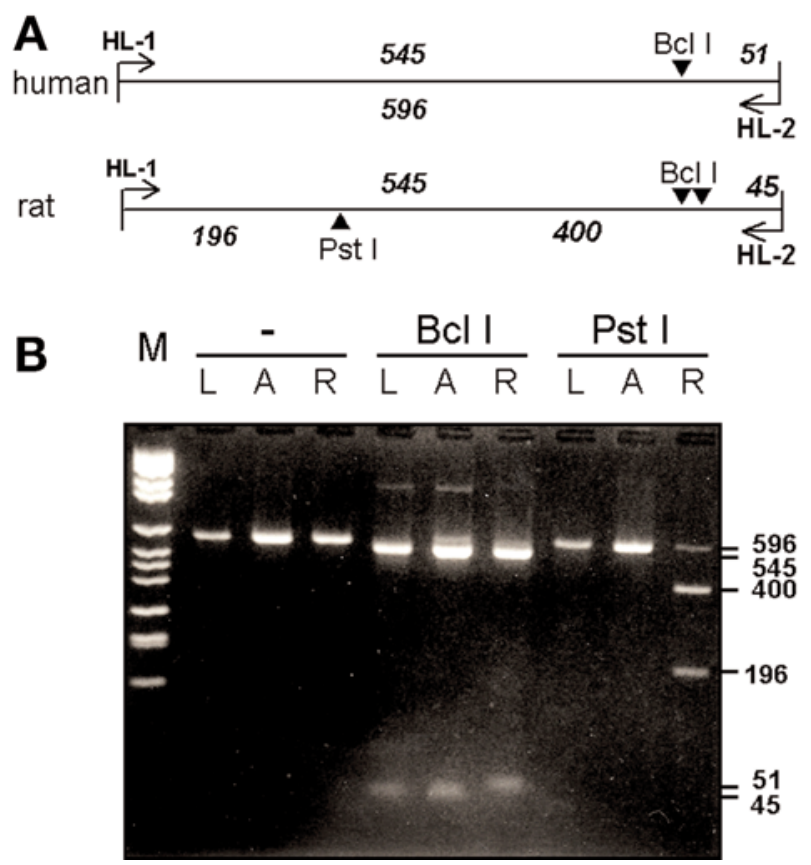

Fig. 1. Detection of hepatic lipase (HL) mRNA in human adrenal glands by reverse-transcription (RT)-PCR. RT-PCR was performed with $1 \mu \mathrm{g}$ of total RNA prepared from human liver (L), from human hyperplastic adrenal (A), and from rat liver (R), using the oligonucleotides HL-1 and HL2 as forward and reverse primer, respectively. After RTPCR, the reaction mixtures were incubated without any restriction enzyme (-), or in the presence of BclI or PstI. A shows the BclI and PstI restriction maps of the 596-bp PCR product deduced from the human and rat HL CDNA sequences $(36,37)$. B shows the RT-PCR and digestion products after separation by agarose gel electrophoresis. DNA size markers were run in the lane marked M. Expected PCR and digestion fragment sizes are indicated in bp. The notemplate and no-RT controls were all negative. Data are representative for three similar experiments.

This suggests that HL mRNA abundance in the human adrenals is similar to rat adrenals, which is 40- to 50fold lower than in rat liver (19). These observations extend our previous report (3) and demonstrate that at least part of the HL mRNA is expressed in human hyperplastic adrenals.

In rat adrenals, exons 1 and 2 of the HL gene are not expressed in the RNA. We tested whether this is also the case for the human adrenals. RT-PCR was performed using HL-2 as downstream primer in combination with different forward primers (Fig. 2A). With HL-8 and HL12 , which are specific for exon- 4 and exon-3, respectively, PCR products were obtained of the expected size, and which hybridized to full-length rat HL cDNA (Fig. 2B). With exon-2-specific HL-13, a 1.0-kb and a 0.85-bp product was generated with RNA from human adrenals
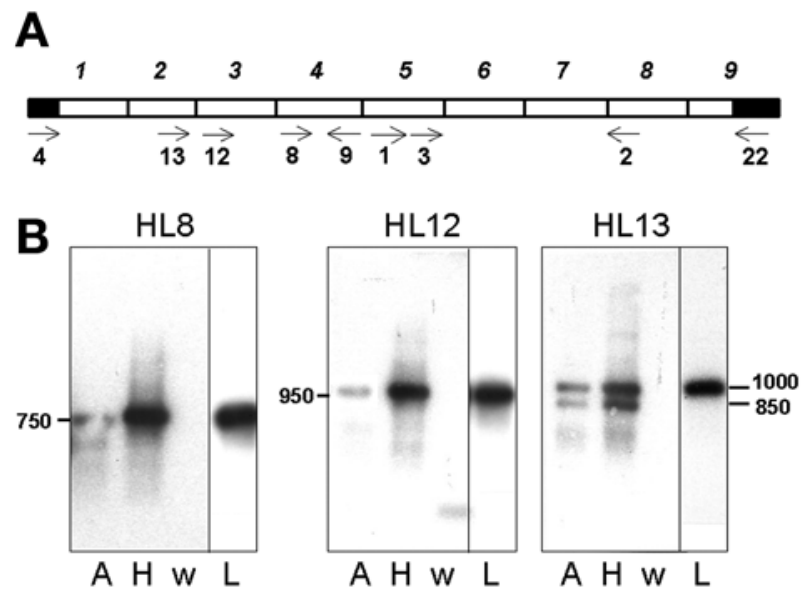

Fig. 2. Southern-blot analysis of HL mRNA from human hyperplastic adrenals after reverse-transcription (RT)-PCR. A schematically shows the exon organization of human hepatic lipase (HL) cDNA. The open bar indicates the coding sequence with the exon numbers given above. The closed bars represent the untranslated regions. The arrows define the position and $5^{\prime} \rightarrow 3^{\prime}$ orientation of all the oligonucleotides used in this study; the primers mentioned in $\mathbf{B}$ are numbered underneath. B shows the results of the RT-PCR analysis. RT-PCR was performed on total RNA from human adrenals (A) and HepG2 cells $(\mathrm{H})$, human liver (L), and on a parallel water control (w). After first-strand DNA synthesis, the incubation was split into three aliquots for amplification with the reverse primer HL-2 and the different forward primers indicated on top of each panel. After gel electrophoresis and blotting, the membranes were probed with ${ }^{32} \mathrm{P}$-labeled rat HL cDNA. The data on human liver are from an overnight exposure to autoradiography film, whereas the other data are from a 48-h exposure. Approximate amplimer sizes are indicated in bp. Data are representative for three independent experiments.

and HepG2 cells. In three independent experiments, the intensity of the $0.85-\mathrm{kb}$ band was $51 \pm 8 \%$ and $57 \pm 14 \%$ of the intensity of the $1.0-\mathrm{kb}$ band with adrenal and HepG2 RNA, respectively. RNA from human liver only generated the 1.0-kb RT-PCR product. Both amplimers were sequenced after cloning into pBluescript. The 1.0$\mathrm{kb}$ band appeared to be identical to the published human HL cDNA sequence. This finding indicates that exon-2 of the HL gene is represented in the RNA from human adrenals, which contrasts with rat adrenals. Additional RT-PCRs with other combinations of primers, including HL-4 and HL-22, demonstrated that in fact, the entire coding part of the HL gene was expressed in the RNA of human hyperplastic adrenals (not shown). The sequence of the $0.85-\mathrm{kb}$ amplimer was 

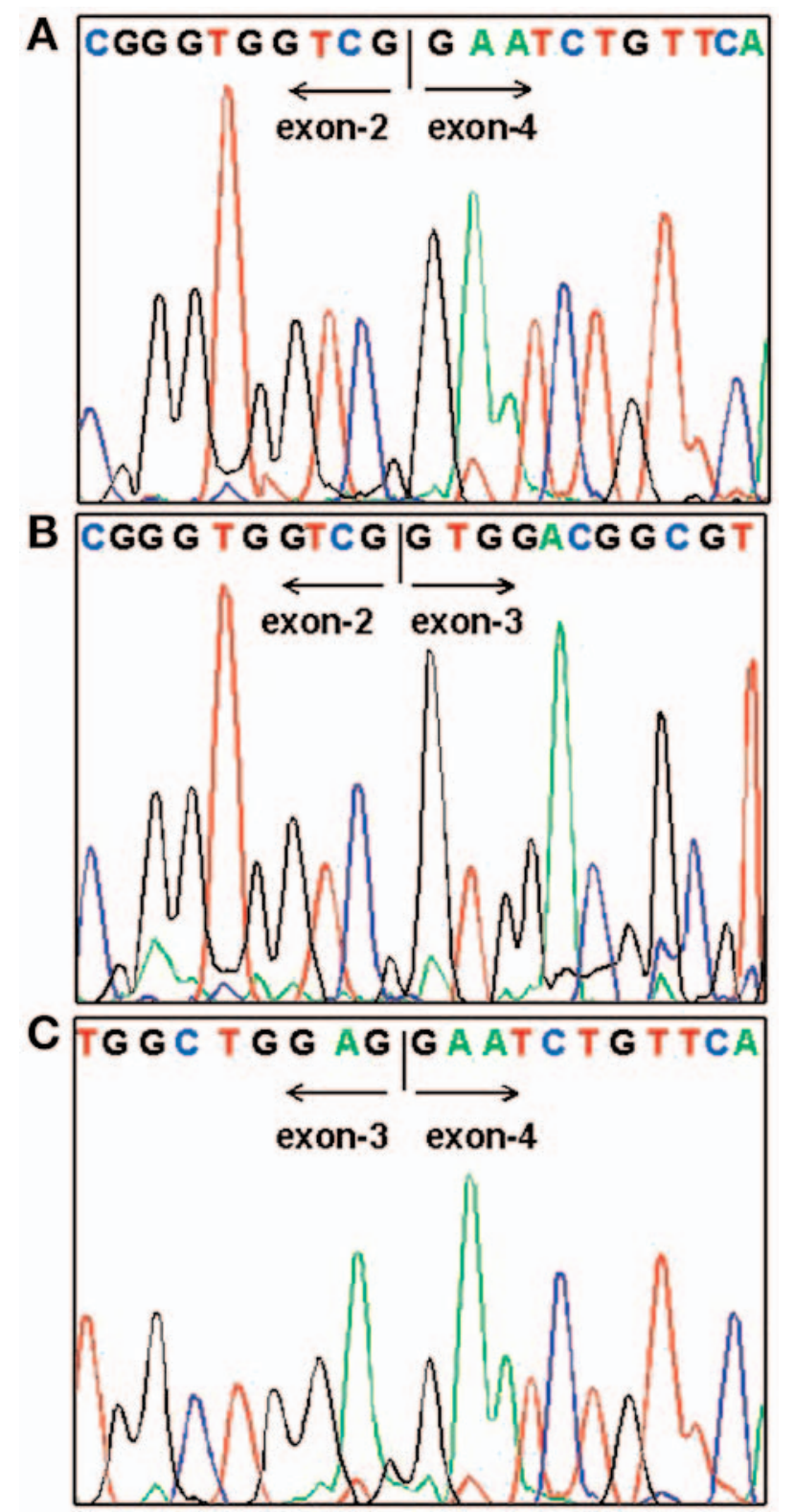

Fig. 3. Exon-3 is skipped in some of the HL gene transcripts in human adrenals. The $0.85-\mathrm{kb}$ reverse-transcription (RT)-PCR product (A) and the 1.0-kb RT-PCR product $(B, C)$ obtained with the HL-13/HL-2 primer pair (cf. Fig. 2B) was gel-purified, TA-cloned into pBluescript, and then analyzed by automated DNA sequencing. The figure shows part of the chromatogram that contained the exon2 /exon- 4 boundary in the $0.85-\mathrm{kb}$ product (A), and the exon-2/exon-3 (B), and exon-3/exon-4 boundaries (C) in the $1.0-\mathrm{kb}$ product.

also identical to human HL cDNA, except that the entire third exon was missing (Fig. 3); in this amplimer exon-2 was immediately followed by exon- 4 .

Finally, we tested whether the human HL gene is transcribed from an alternative promoter within
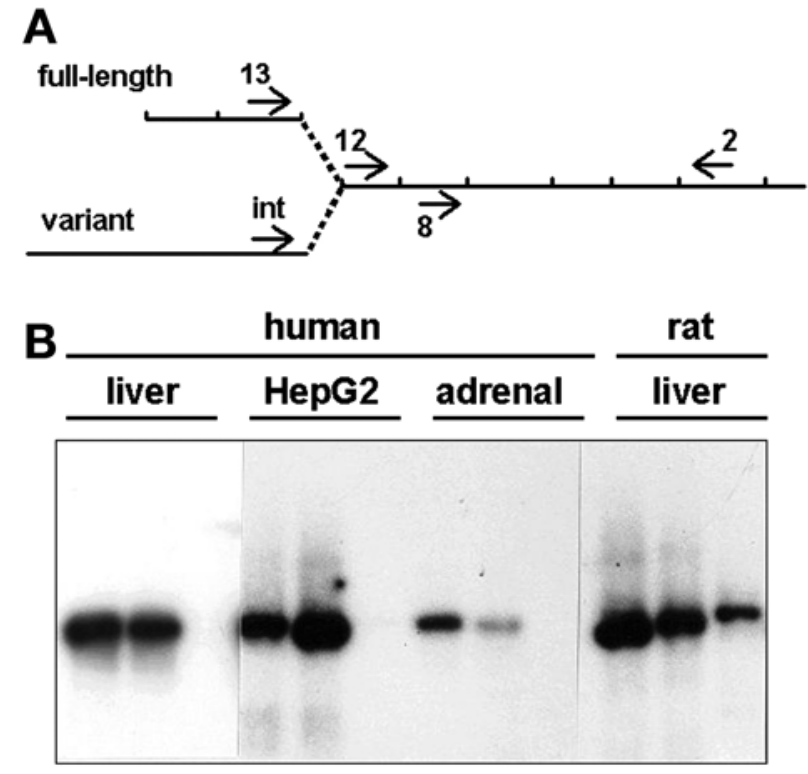

1213 int 1213 int 1213 int 1213 int

Fig. 4. Intron-2 sequence is not expressed in hepatic lipase (HL) mRNA from human adrenals or liver. Reversetranscription (RT)-PCR was performed on RNA from human liver, HepG2 cells, and hyperplastic adrenals. In combination with HL-2, different forward primers were used that are specific either for exon-3 (HL-12), exon-2 (HL-13), or intron-2 (int). In parallel, a similar set of incubations was performed with RNA from rat liver using primers specific for the homologous regions in the rat HL gene. After separating the PCR-mixtures on an agarose gel, the DNA was blotted to Hybond-N and the membrane was probed with ${ }^{32}$ P-labeled HL-8 oligonucleotide. A schematically shows the position of the used oligonucleotides in human and rat HL cDNA. B shows an autoradiogram of the resulting blot. Data are representative for two independent experiments.

intron-2, as described for the rat gene $(19,22)$. RT-PCR was performed using HL-2 in combination with the oligonucleotide int, which recognizes intron-2 immediately upstream of exon-3, and which is used routinely in our laboratory in the amplification of exon-3 from genomic DNA. No products were observed when total RNA was used from either human adrenals, HepG2 cells, or human liver (Fig. 4). In parallel reactions, PCR products of the expected size that hybridized with an internal probe were generated with HL-12 and HL-13 as forward primers. Analogous RT-PCR reactions on rat liver RNA gave good yields with all three forward primers tested, including the intron-2 primer. Hence, transcription from an alternative promoter in intron-2, as described for the rat HL gene, is not evident in human adrenals, human liver or HepG2 cells. 


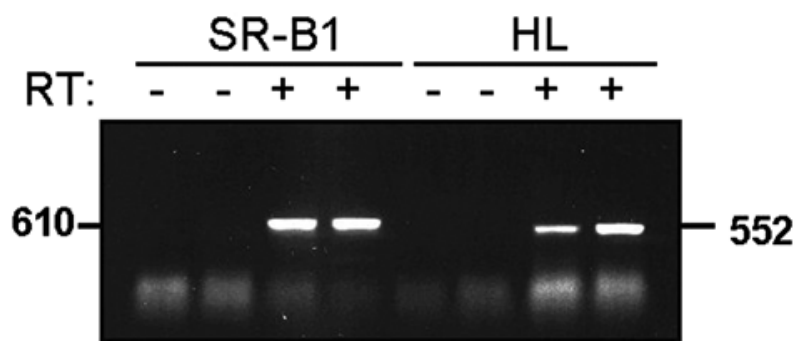

Fig. 5. Hepatic lipase (HL) mRNA is expressed in the NCI-H295R human adrenocortical cell line. Reversetranscription (RT)-PCR was performed on RNA prepared from two independent human NCI-H295R cell cultures, without (-) or with (+) reverse transcriptase in the RT reaction. Amplification was for 45 cycles using either SR-B1-specific primers, or the HL specific primers HL-2 and HL-3; PCR products were separated by agarose gel electrophoresis. The expected amplimer sizes are indicated in bp.

\section{Human Adrenocortical Cell Line}

After 45 cycles of amplification, RT-PCR on RNA from NCI-H295R adrenocortical cells with the HL2/HL-3 primer pair yielded the expected 552-bp product (Fig. 5). This PCR product was not visible in ethidiumbromide-stained gels after 35 cycles of amplification used routinely, suggesting that the abundance of HL mRNA is less than in HepG2 cells or hyperplastic adrenals. For comparison, we also used oligonucleotides specific for human SR-B1 in the RT-PCR. A product of the expected size $(610 \mathrm{bp})$ was readily obtained, confirming previous reports that SR-B1 is expressed in this cell line (29).

To determine the transcriptional activity of the human HL promoter region in NCI-H295R adrenocortical cells, cells were transiently transfected with reporter plasmids containing a 698-bp or a 325-bp fragment (Fig. $6)$. Both HL promoter fragments showed almost threefold higher activity than the promoter-less pCAT-Basic. The activity of the 698-bp HL promoter fragment in the adrenocortical cells was comparable to that in the human hepatoma HepG2 cells. Shortening the HL promoter fragment from 698 bp to 325 bp left transcriptional activity in adrenocortical cells unaffected, whereas the activity in HepG2 cells was further increased. Similarly, the rat HL446 promoter fragment was active in both cell types, but CAT expression was much higher in the HepG2 than in the NCI-H295R cells. Compared to the conventional human and rat HL promoter fragments, the alternative rat HL promoter in intron-2 showed negligible activity in this reporter assay (Fig. 6). Treatment of transfected NCI-H295R cells with $0.4 \mathrm{mU} / \mathrm{mL}$ ACTH slightly but insignificantly increased transcriptional activity of the HL698 construct (1.3- \pm 0.4 -fold increase; $n$



Fig. 6. Hepatic lipase (HL) promoter activity in transiently transfected HepG2 and NCI-H295R cells. The indicated promoter-CAT reporter plasmids were transfected into HepG2 and NCI-H295R cells (open en closed bars, respectively). At $48 \mathrm{~h}$ posttransfection, CAT and $\beta$-galactosidase expression was determined. The CAT data were normalized on the basis of $\beta$-galactosidase expression. Normalized CAT data are expressed as fold increase with respect to the promoter-less pCAT-Basic. Data are means $\pm \mathrm{SD}$ for three independent experiments. The asterisks indicate a statistically significant difference from pCATBasic $(\underline{p}<0.05)$.

= 3; not significant). As shown in Fig. 7, incubation of the cells with membrane-permeant 8-Br-cAMP, which mimics the effect of the corticotropin, increased the activity of the HuHL698 promoter fragment 1.9- \pm 0.2 -fold $(n=3 ; p$ $<0.05)$, and that of the HuHL325 construct 1.7- \pm 0.3 -fold $(n=3 ; p<0.05)$. Hence, the conventional HL promoter region is active in the human adrenocortical cells, and sensitive to regulation by cAMP.

\section{DISCUSSION}

The presence of HL activity in the adrenal cortex of humans and other mammals, as well as in ovaries, has long been recognized. In the rat, several attempts to determine HL mRNA or HL de novo synthesis in these steroidogenic organs have been unsuccessful $(7,9,18,19)$. This led to the hypothesis that this lipase actually is synthesized in the liver and subsequently transported to the steroidogenic organs $(4,7,9)$. Here, we show for the first time that full-length HL mRNA is expressed in the hyperplastic adrenals of patients with Cushing's disease. These adrenals are activated by increased pituitary secretion of ACTH, and contain elevated levels of HL activity $(30,31)$. We corroborated these findings by promoter-reporter assays using the human adrenocortical NCI-H295R cell 


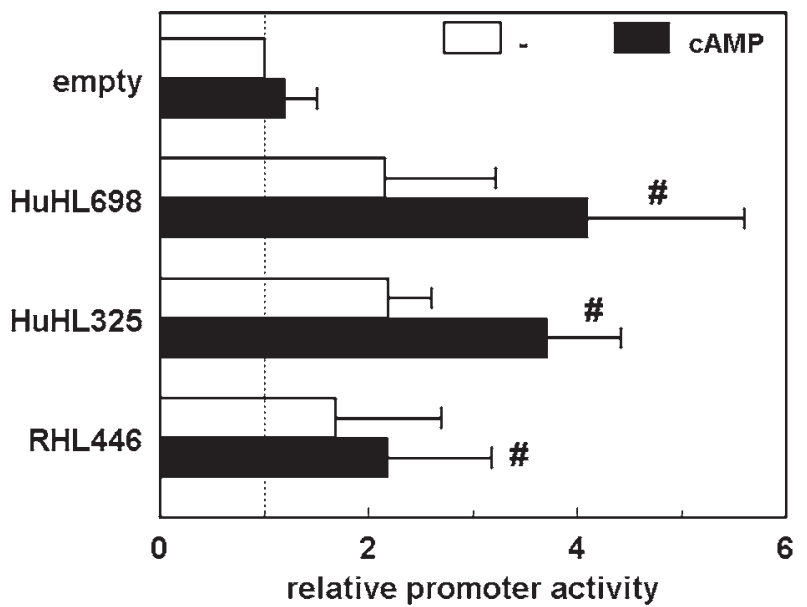

Fig. 7. Effect of 8-Br-cAMP on hepatic lipase promoter activity in NCI-H295R cells. Experiments were performed as described in the legends to Fig. 6, except that cells were incubated in the presence (filled bars) or absence (open bars) of $300 \mu M$ 8-Br-cAMP. Data are means \pm SD for three to four independent experiments. \#, statistically significant effect of 8 -Br-cAMP $(p<0.05)$, as determined by paired Student $t$-test.

line. These assays demonstrated that the human HL promoter region is active in these cells, and that promoter activity in these cells is enhanced by 8-Br-cAMP, which mimics the effect of ACTH. An increased HL expression in these organs may be important to maintain the high steroid production, possibly by accelerating the SR-BI mediated uptake of HDL cholesterol $(6,14,16,17)$. The presence of full-length HL mRNA in these activated adrenals strongly suggests that at least part of the adrenal HL activity originates from local synthesis.

The presence of full-length HL mRNA in the human adrenals contrasts with the situation in rat adrenals $(19,22)$ and ovaries $(20)$, where only a variant HL gene transcript is found. This variant HL mRNA is also present in rat liver, but at a low abundance relative to fulllength HL mRNA (19), and originates from the usage of an alternative promoter in intron-2 (22). In the present study, no evidence was found for the expression of its counterpart in human adrenals or in human liver. In this respect, the situation in the rat steroidogenic organs appears to be unique to rat.

In human adrenals as well as in HepG2 cells, a small fraction of the HL gene transcripts lacks exon-3. The open reading frame of this alternative splice product is maintained (25), which would result in a markedly shorter translation product. Because exon-3 is at the heart of the catalytic domain of HL, it is unlikely that this alternative translation product is properly folded, let alone catalytically active (32). The alternatively spliced RNA was not observed with the human liver preparation. Hence, alternative splicing of the primary HL gene transcript may reflect the altered phenotype of the hyperplastic adrenal and the HepG2 hepatoma cells rather than imply functional significance. Therefore, no attempts were made to demonstrate expression of the alternative translation product in either HepG2 cells or human adrenals.

In conclusion, we have shown here that human hyperplastic adrenals express full-length HL mRNA. In the human, adrenal HL may therefore not only originate from liver $(4,7)$, but may also be locally synthesized. The presence of HL mRNA and secretion of HL activity has been reported for human pre-ovulatory granulosa cells (33), suggesting that HL is locally synthesized in ovarian cells as well. Within the adrenal glands, HL activity is predominantly localized in the steroidogenic cortex $(1,2)$, and is required for optimal selective uptake of HDL cholesterol by adrenocortical cells (16). In HL-null mice, the ACTH-induced increase in plasma corticosterone levels was attenuated, suggesting that adrenal HL is important for steroidogenesis (34). In patients with Cushing's disease, adrenal HL activity is severalfold higher than in controls $(30,31)$, and the daily cortisol production is increased in parallel (30). Taken together, these observations strongly suggest that adrenal HL has an important role in cholesterol supply for steroid production (34). HL may facilitate the selective uptake of free cholesterol $(12,35)$, or of cholesteryl esters via the HDL/SR-B1 (17) and low-density lipoprotein (LDL)-receptor pathways (34).

\section{ACKNOWLEDGMENTS}

We wish to thank Dr. L. Hofland, P. van Koetsveld, and Prof. Dr. Th. Visser, Department of Internal Medicine, Erasmus MC, for collection of patient material. We are grateful to Dr. B. Staels, Pasteur Institute, Lille, France, for his kind gift of the NCI-H295R cells. Part of this study was supported by the Dutch Heart Foundation (grant nr. 94.064).

\section{REFERENCES}

1. Cordle, S. R., Yeaman, S. J., and Clegg, R. A. (1983) Saltresistant (hepatic) lipase: evidence for its presence in bovine liver and adrenal cortex. Biochim. Biophys. Acta 753, 213-219.

2. Persoon, N. L. M., Hülsmann, W. C., and Jansen, H. (1986) Localization of the salt-resistant heparin-releasable lipase in rat liver, adrenal and ovary. Eur. J. Cell Biol. 41, 134-137.

3. Verhoeven, A. J. M. and Jansen, H. (1994) Hepatic lipase mRNA is expressed in rat and human steroidogenic organs. Biochim. Biophys. Acta 1211, 121-124. 
4. Galan, X., Peinado-Onsurbe, J., Julve, J., et al. (2003) Inactive hepatic lipase in rat plasma. J. Lipid Res. 44, 2250-2256.

5. Jansen, H. and De Greef, W. J. (1981) Heparin-releasable lipase activity of rat adrenals, ovaries and testes. Biochem. J. 196, 739-745.

6. Gåfvels, M., Bengtsson-Olivecrona, G., and Olivecrona, T. (1989) Correlation of plasma progesterone concentration to ovarian H-type lipase activity during pseudopregnancy in the rat. J. Reprod. Fertil. 86, 589-598.

7. Hixenbaugh, E. A., Sullivan, T. R. Jr., Strauss, J. F. $3^{\text {rd }}$, Laposata, E. A., Komaromy, M., and Paavola, L. G. (1989) Hepatic lipase in the rat ovary. Ovaries cannot synthesize hepatic lipase but accumulate it from the circulation. J. Biol. Chem. 264, 4222-4230.

8. Wade, R. L., Van Andel, R. A., Rice, S. G., Banka, C. L., and Dyer, C. A. (2002) Hepatic lipase deficiency attenuates mouse ovarian progesterone production leading to decreased ovulation and reduced litter size. Biol. Reprod. 66, 1076-1082.

9. Doolittle, M. H., Wong, H., Davis, R. C., and Schotz, M. C. (1987). Synthesis of hepatic lipase in liver and extrahepatic tissues. J. Lipid Res. 28, 1326-1334.

10. Schultz, C. J., Blanchette-Mackie, E. J., and Scow, R. O. (2000) Adrenal and liver in normal cld/cld mice synthesize and secrete hepatic lipase, but the lipase is inactive in cld/cld mice. J. Lipid Res. 41, 214-225.

11. Santamarina-Fojo, S., González-Navarro, H., Freeman, L., Wagner, E., and Nong, Z. (2004) Hepatic lipase, lipoprotein metabolism, and atherogenesis. Arterioscler. Thromb. Vasc. Biol. 24, 1-5.

12. Bamberger, M., Glick, M., and Rothblat, G. H. (1983) Hepatic lipase stimulates the uptake of HDL cholesterol by hepatoma cells. J. Lipid Res. 24, 869-876.

13. Marques-Vidal, P., Azéma, C., Collet, X., Vieu, C., Chap, H., and Perret, B. (1994) Hepatic lipase promotes the uptake of HDL esterified cholesterol by the perfused rat liver: a study using reconstituted HDL particles of defined phopholipid composition. J. Lipid Res. 35, 373-384.

14. Jansen, H. and Hülsmann, W. C. (1980) Heparinreleasable (liver) lipase(s) may play a role in the uptake of cholesterol by steroid-secreting tissues. Trends Biochem. Sci. 5, 265-268.

15. Jansen, H. and De Greef, W. J. (1988) L-type lipase activity in ovaries of superovulated rats. Mol. Cell. Endocrinol. 57, 7-15.

16. Wang, N., Weng, W., Breslow, J. L., Tall, A. R. (1996). Scavenger receptor BI (SR-BI) is up-regulated in adrenal gland in apolipoprotein A-I and hepatic lipase knock-out mice as a response to depletion of cholesterol stores. In vivo evidence that SR-BI is a functional high density lipoprotein receptor under feedback control. J. Biol. Chem. 271, 21,001-21,004.

17. Lambert, G., Chase, M. B., Dugi, K., Bensadoun, A., Brewer, H. B. Jr., and Santamarino-Fojo, S. (1999) Hepatic lipase promotes the selective uptake of high-density lipoprotein-cholesteryl esters via the scavenger receptor B1. J. Lipid Res. 40, 1294-1303.

18. Semenkovich, C. F., Chen, S.-H., Wims, M., Luo, C.-C., Li, W.-H., and Chan, L. (1989) Lipoprotein lipase and hepatic lipase mRNA tissue specific expression, developmental regulation, and evolution. J. Lipid Res. 30, 423-431.

19. Verhoeven, A. J. M., Carling, D., and Jansen, H. (1994) Hepatic lipase gene is transcribed in rat adrenals into a truncated mRNA. J. Lipid Res. 35, 966-975.

20. Vieira-van Bruggen, D., Verhoeven, A. J. M., Heuveling, M., Kalkman, C., De Greef, W., and Jansen, H. (1997) Hepatic lipase gene expression is transiently induced by gonadotropic hormones in rat ovaries. Mol. Cell. Endocrinol. 126, 35-40.

21. González-Navarro, H., Nong, Z., Freeman, L., Bensadoun, A., Peterson, K., and Santamarina-Fojo, S. (2002) Identification of mouse and human macrophages as a site of synthesis of hepatic lipase. J. Lipid Res. 43, 671-675.

22. Botma, G.-J., Vieira, D., Heuveling, M., Jansen, H., and Verhoeven, A. J. M. (2006) Transient induction of a variant hepatic lipase messenger RNA by corticotropic hormone in rat adrenals. Metabolism 55, 467-477.

23. Chomczynski, P. and Sacchi, N. (1987) Single-step method of RNA isolation by acid guanidinium thiocyanate-phenol-chloroform extraction. Anal. Biochem. 162, 156-159.

24. Sambrook, J., Fritsch, E. F., and Maniatis, T. (1989) Molecular Cloning, a Laboratory Manual. $2^{\text {nd }}$ Ed. Cold Spring Harbor Laboratory Press, Cold Spring Harbor, NY.

25. Ameis, D., Stahnke, G., Kobayashi, J., et al. (1990) Isolation and characterization of the human hepatic lipase gene. J. Biol. Chem. 265, 6552-6555.

26. Calvo, D. and Vega, M. A. (1993) Identification, primary structure, and distribution of CLA-1, a novel member of the CD36/LIMPII gene family. J. Biol. Chem. 268, 18,929-18,935.

27. Marchuk, D., Drumm, M., Saulino, A., Collins, F. S., (1991) Construction of T-vectors, a rapid and general system for direct cloning of unmodified PCR products. Nucleic Acids Res. 19, 1154.

28. Botma, G.-J., Verhoeven, A. J. M., and Jansen, H. (2001) Hepatic lipase promoter activity is reduced by the C-480T and G-216A substitutions present in the common LIPC gene variant, and is increased by Upstream Stimulatory Factor. Atherosclerosis 154, 625-632.

29. Martin, G., Pilon, A., Albert, C., et al. (1999) Comparison of expression and regulation of the high-density lipoprotein receptor SR-BI and the low-density lipoprotein receptor in human adrenocortical carcinoma NCI-H295 cells. Eur. J. Biochem. 261, 481-491.

30. Jansen, H. and Birkengäger, J.C. (1981) Liver lipase-like activity in human and hamster adrenocortical tissue. Metabolism 30, 428-430.

31. Berg, A. L., Hansson, P., and Nilsson-Ehle, P., 1990. Salt resistant lipase activity in human adrenal gland is increased in Cushing's disease. J. Intern. Med. 228, 257-260.

32. Dugi, K. A., Dichek, H. L., and Santamarina-Fojo, S. (1995) Human hepatic and lipoprotein lipase: the loop covering the catalytic site mediates lipase substrate specificity. J. Biol. Chem. 270, 25,396-25,401.

33. Perret, B., Mabile, L., Martinez, L., Tercé, F., Barbaras R., and Collet, X. (2002) Hepatic lipase: structure/function relationship, synthesis, and regulation. J. Lipid Res. 43, 1163-1169. 
34. Dichek, H.L., Agrawal, N., El Andaloussi, N., and Qian, K. (2006) Attenuated Corticosterone Response to Chronic ACTH Stimulation in Hepatic Lipase-deficient Mice: Evidence for a Role for Hepatic Lipase in Adrenal Physiology. Am. J. Physiol. Endocrinol. Metab. 290, E908-E915.

35. Vieira-van Bruggen, D., Kalkman, I., van Gent, T., van Tol, A., and Jansen, H. (1998) Induction of adrenal scavenger receptor BI and increased high density lipoprotein-choles- teryl ether uptake by in vivo inhibition of hepatic lipase. $J$ Biol. Chem. 273, 32,038-32,041.

36. Komaromy, M. C. and Schotz, M. C. (1987) Cloning of rat hepatic lipase cDNA: evidence for a lipase gene family. Proc. Natl. Acad. Sci. USA 84, 1526-1530.

37. Martin, G. A., Busch, S. J., Meredith, G. D., et al. (1988). Isolation and cDNA sequence of human postheparin plasma hepatic triglyceride lipase. J. Biol. Chem. 263, $10,907-10,914$. 